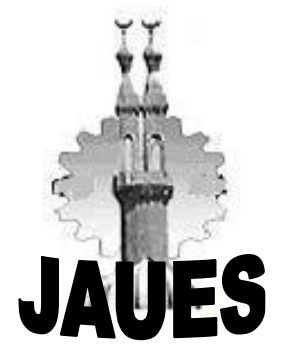

Journal of Al Azhar University Engineering Sector

Vol. 14, No. 52, July 2019, 994-1002

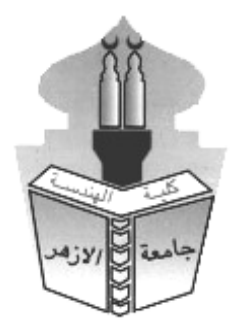

\title{
PRO-AGING NEIGHBORHOOD STREETS AND PATHWAYS
}

\author{
Hosam Kotb El Ghorab \\ Department of Architectural Engineering, Faculty of Engineering - Zagazig University - EGYPT \\ E-mail: hosamkotb@yahoo.com
}

\begin{abstract}
With the increase of health services efficiency around the world, it is expected that death rate will be minimized and human age will be maximized, consequently number of aging people will be increased. These aging people have their own needs in the streets and pathways of the Neighborhoods they are live in. This Paper aims to make the streets and pathways of the Neighborhoods more responsive to aging people's needs by identifying these needs and integrating it in the Neighborhoods planning criteria. The paper consists of five main steps. The first step focuses on paper introduction, including research problem description, objectives and importance of research, research boundaries, and methodological procedures. The second step is to define the research key concepts and terms. The third step focuses on difficulties of aging people with Neighborhood streets and pathways. The fourth point focuses on identifying aging people's needs in these streets and pathways. The fifth and final step focuses on the results and recommendations of the paper to making the streets and pathways of the Neighborhoods more responsive to aging people's needs.
\end{abstract}

\section{KEYWORDS: Pro-Aging; Aging People; Neighborhood; Streets And Pathways}

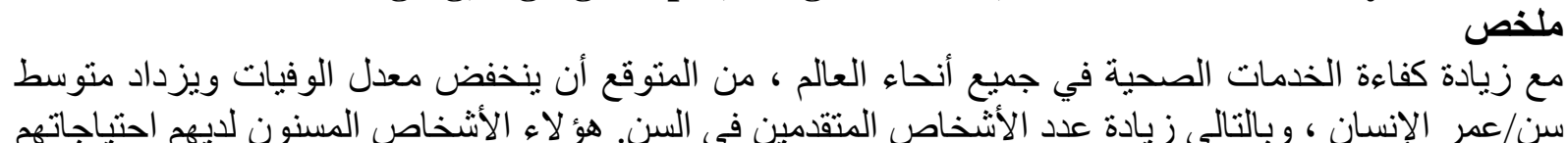

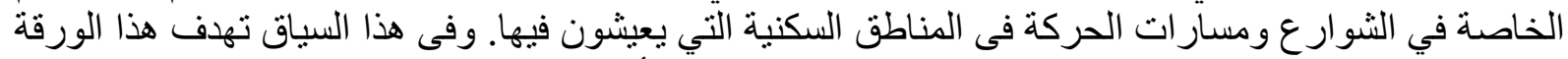

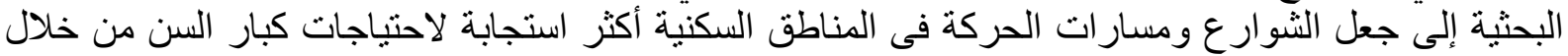

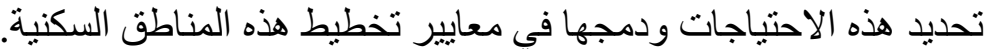

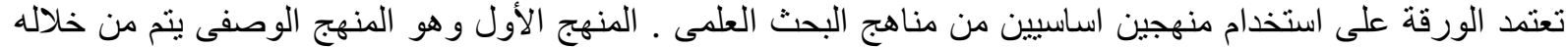

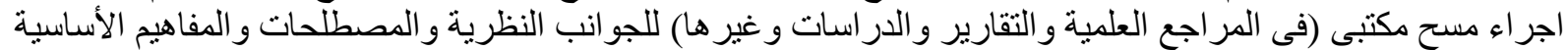

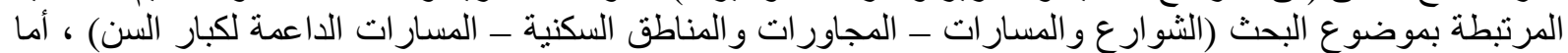

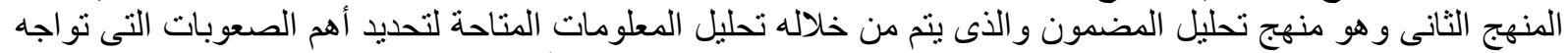

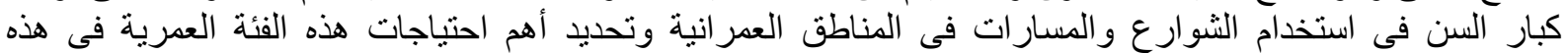

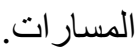

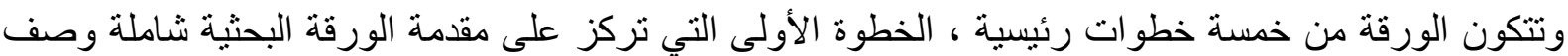

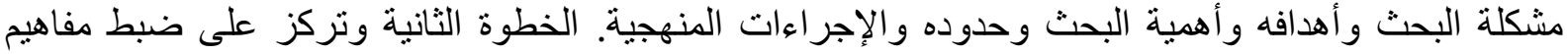

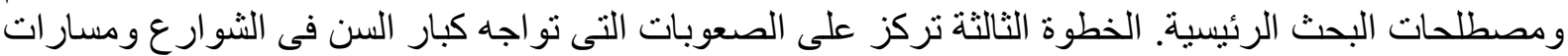

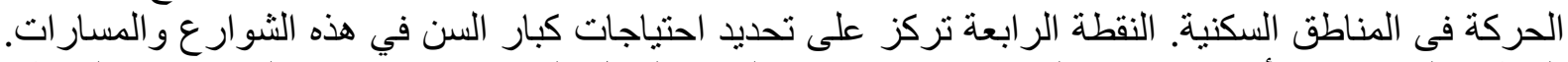

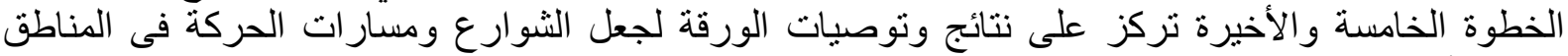
السكنية أكثر استجابة لاحتياجات كبار السن.

$$
\text { الكلمات الإفتتاحية: الداعمة لكبار السن - كبار السن - المجاورة السكنية ـ المسارات والثوارع }
$$




\section{1) INTRODUCTION \\ BACKGROUND}

The composition of the world population has changed in recent decades. Worldwide life expectancy rose from 46 years (in 1950) to 68 years (in 2010), and it is projected to increase to 81 years by the end of the century [1]. In 2015, there are 901 million people aged 60 or over, comprising 12 per cent of the global population [2], and in 2017 the number of aging people becomes 962 million person [3]. The increase in the number of aging people will be the greatest and the most rapid in the developing world [1].

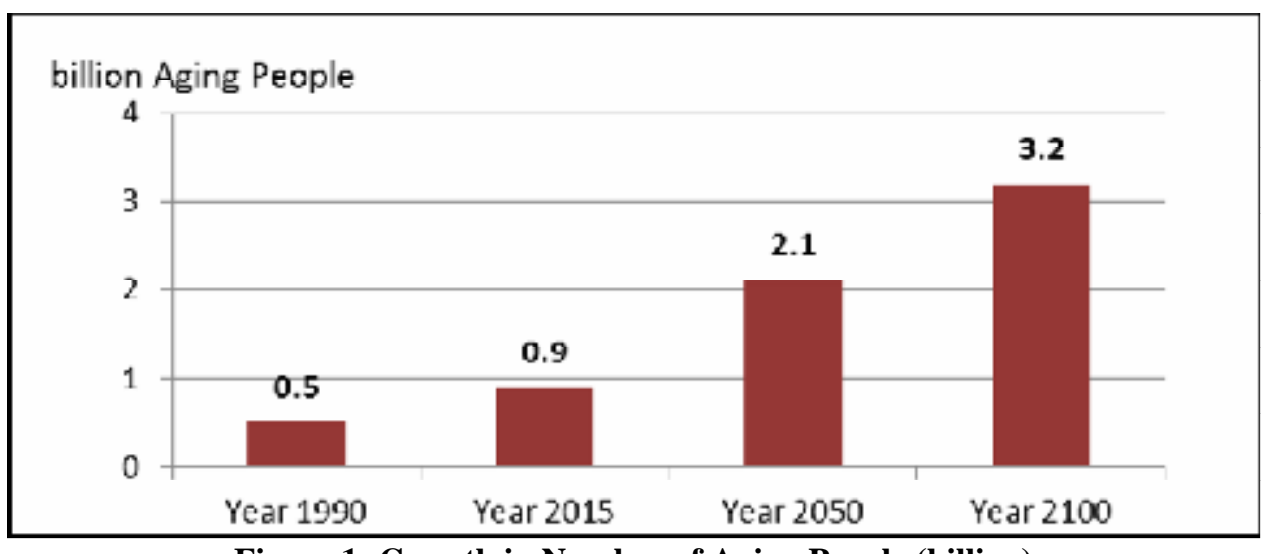

Figure 1: Growth in Number of Aging People (billion)

Source: (UNDESA-PD, 2015)

In this context, we should pay more attention to aging people needs in the Neighborhoods streets and pathways they are living in to make it more comfortable and suitable for them.

\section{Research Problem \& Importance}

The main problem discussed in this paper is that the aging people's needs in the streets and pathways of the Neighborhoods are not fully considered in the neighborhoods planning and design. Consequently, aging people can't feel comfort in their neighborhoods in many parts of the world, especially in developing countries. This paper is important for two reasons. First reason is that these people are the most vulnerable groups in society and they need for great care. The second reason is that these people comprise about 12 per cent of the global population.

\section{Research Objectives}

The essential goal of this Paper is making the streets and pathways of the Neighborhoods more comfort to aging people by making it more responsive to their needs. The secondary objectives include identifying difficulties of aging groups with these streets and pathways, and determining their needs in it, in order to integrate it in the planning criteria of the Neighborhoods.

\section{Research Boundaries}

There are three boundaries of this paper. First is the objective boundary which focuses on the responsiveness of the Neighborhoods' streets and pathways to the needs of aging people. Second is the spatial boundary which includes all cities all over the world. Third is the temporal boundary which focuses on the current and future time.

\section{Research Methodology and Structure}

This paper adopts two approaches of research methods. First is the descriptivel qualitative approach through which an office survey is done in scientific references to collect data on the theoretical aspects related to the research subject (streets and pathways - neighborhoods and residential areas - Pro-aging streets and pathways). The second approach is the content analysis approach, in which the available information is analyzed to identify the most important difficulties facing aging people in the use of streets and pathways and to identify their important needs in this age group in this regard. 
The structure of the paper consists of five main points: First point focuses on paper introduction including research problem description, objectives and the importance of research, research boundaries, and methodological procedures. The second point is to adjust the research key concepts and terms. The third point focuses on difficulties of aging people with Neighborhood streets and pathways. The fourth point focuses on identifying aging people's needs in the streets and pathways of the Neighborhoods. The fifth point focuses on final results and recommendations to make Neighborhoods' streets and pathways more responsive to aging people's needs.

\section{2) CONCEPTS AND TERMS}

\section{Aging people}

Aging is a biological process occurred outside human control. In many developing countries, old age is seen to begin at the point when active contribution is no longer possible [4]. This point usually occurs between the ages of 45 and 55 years for women and between the ages of 55 and 75 years for men [5]. On the other hand an international anthropological study, was conducted in the late 1970's in multiple areas of Africa, provided a three basis for a definition of old age in developing countries: 1) chronology; 2) change in social role (i.e. change in work patterns, adult status of children and menopause); and 3) change in capabilities (i.e. invalid status, senility and change in physical characteristics) [6].

\section{Neighborhood}

The concept of the neighborhood unit considered as one of the most intellectual works appeared in the early 20th century. It was designed by "Clarence Perry" to act as a framework for urban planners attempting to divide the city into smaller functional, self-contained and desirable subareas (neighborhoods) in industrializing cities. Perry conceived of neighborhoods in that period as islands locked amidst a burgeoning sea of vehicular traffic, a dangerous obstacle which prevented aging people, children and adults from safely walking to nearby services, amenities and open spaces [7][8].

Researchers around the world have not agreed upon a single definition of the "neighborhood unit". Neighborhood, or community, can be described as a "circle of people who live together, who belong together so that they share a whole set of interests wide enough and complete enough to include their lives" [9][10]. Neighborhood can also be defined as a specific geographic area and functionally as a set of social networks [11]. The neighborhood unit may also be defined as a housing mix that includes the required public services, and is served by a basic school [12].

\section{Neighborhood streets and pathways}

There are many definitions of the streets and pathways. It could be described as boulevards, avenues, streets, walks, and alleys that connect the places and knit the city together [13]. Also, pathways could be described as networks of habitual or potential lines of movement through the urban complex. These lines act as linear spaces that allow individuals walk and recognize the different elements of the city [14]. And also, Pathways are not merely a linear vacuum in which individuals move from one point to another, or simply a path to utility networks, but they are essential elements in building the city and giving it its own character [15] .

\section{3) DIFFECULTIES $\backslash$ PROBLEMS OF AGING PEOPLE WITH NEIGHBORHOOD STREETS AND PATHWAYS}

There was a research aims to offer design guidance, based on rigorous research investigating people's views and preferences, on creating environments that maximize people's quality of life. In this research, a number of aging people "participants" were asked to identify any problems they face when they go out and use their neighborhood streets and pathways. Their responses fell into five different categories. First category (represents $40 \%$ of the participants) could not identify any problems at all. Second category (represents $25 \%$ of the participants) answered with difficulties in walking. Third category (represents $23 \%$ of the participants) answered with fear of falling on the ground. Fourth category (represents $10 \%$ of the participants) answered with difficulties in crossing roads. Fifth category (represents $2 \%$ of the participants) answered with Fear of getting lost. [16]. 


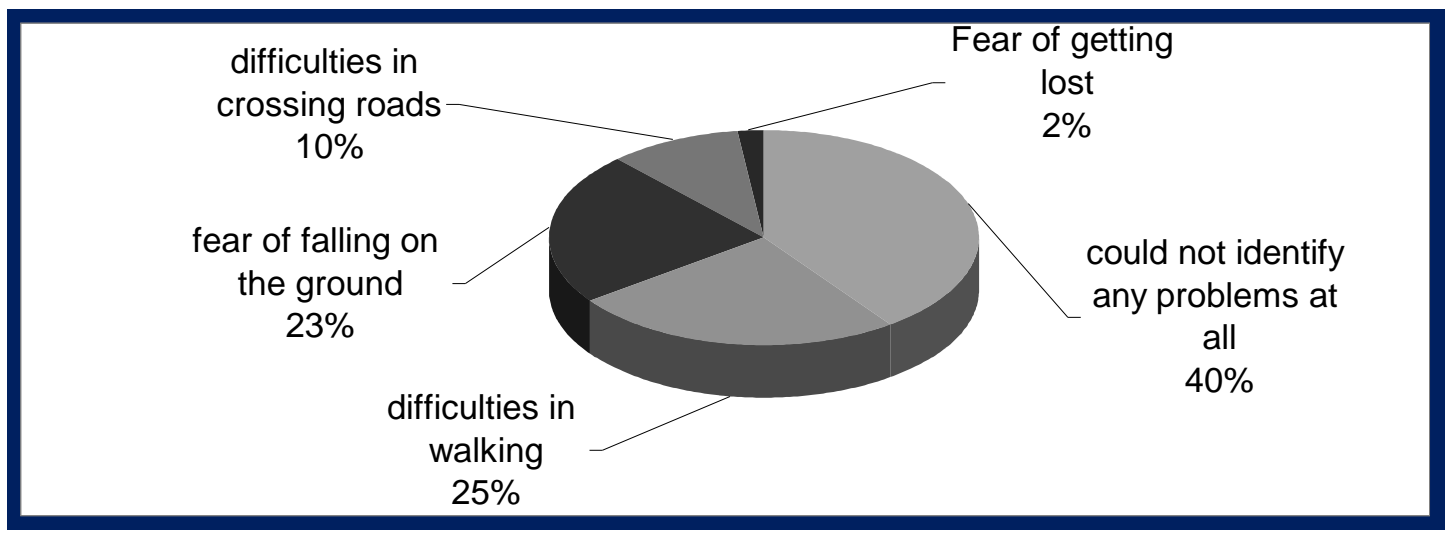

Figure 2: Aging people answers to identify their problems in using their neighborhood streets and pathways Source: The Researcher according to (Elizabeth Burton and Lynne Mitchell., 2006)

Difficulties in walking were seen to stem from their own impairments and disabilities, but also from steep slopes and steps in the local neighborhood. Some people felt the problem is because shops, bus stops and facilities are too far away or because there are not enough public seats for resting en route. The fear of falling again stems partly from personal impairments such as poor eyesight or general frailty, but participants also identified uneven or slippery surfaces, cyclists on pavements, road/pavement works and lack of dropped kerbs as causes. Crossing roads is seen to be made more difficult by dangerous, speeding, heavy traffic, or crossings not being in the right places. [16]
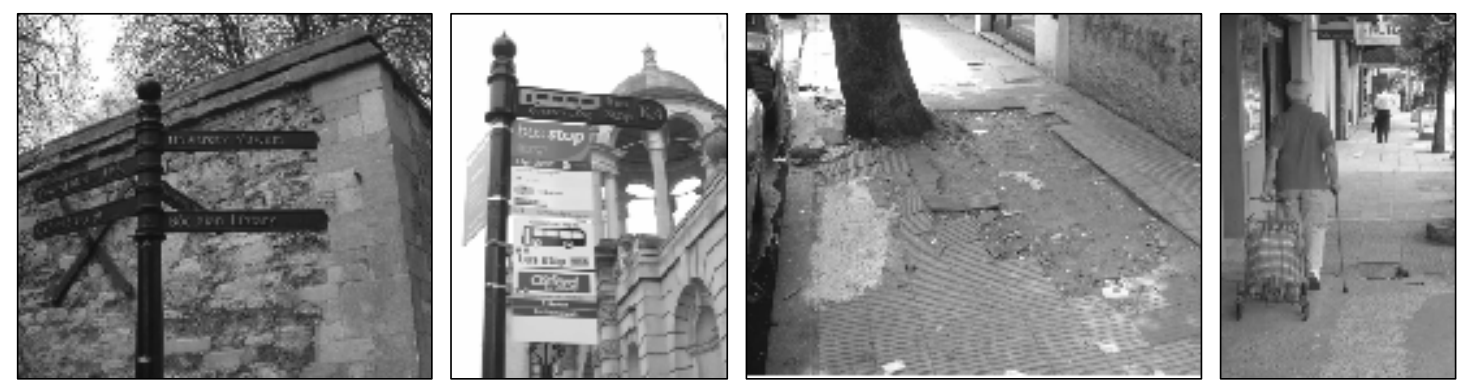

Figure 3: Problems of aging people with their neighborhood streets and pathways

Left: Unclear signs are difficult for aging people to read because the graphics are too small, too high or have multiple pointers that can be ambiguous.

Right: Badly designed or maintained streets - Uneven or damaged streets surfaces - can be a problem for anyone but especially for aging people Source: (Elizabeth Burton and Lynne Mitchell., 2006)

Focusing on road safety, global status report on road safety 2013 indicates that Road traffic crashes kill about 1.24 million people each year. About 273 000, represents around 22\%, of these killed people are pedestrians [17]. Many factors are involved in road traffic crashes, include but not limited to: [18]

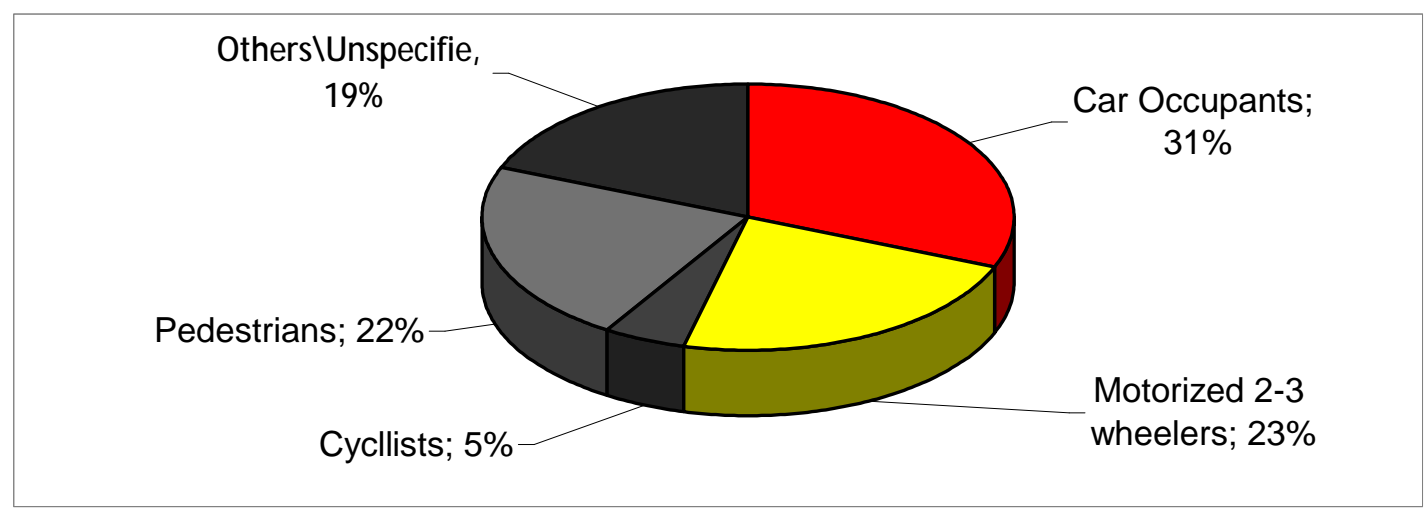

Figure 4: Distribution of road traffic deaths by type of road user, global, 2010 Source: (WHO, 2013a) 
- Factors related to the driver (age, sex, alcohol level, number of people in the vehicle);

- Factors related to the road and vehicle (road layout, surface quality, vehicle power, maximum speed); and

- Factors related to the traffic and environment (traffic density and composition, prevailing speed, weather conditions).

- Factors related to inadequate visibility of pedestrians, which arises from inadequate roadway lighting, unequipped Vehicles and bicycles with lights, dark and unreflective pedestrians' clothes, and Pedestrians sharing road space with fast-moving vehicles.
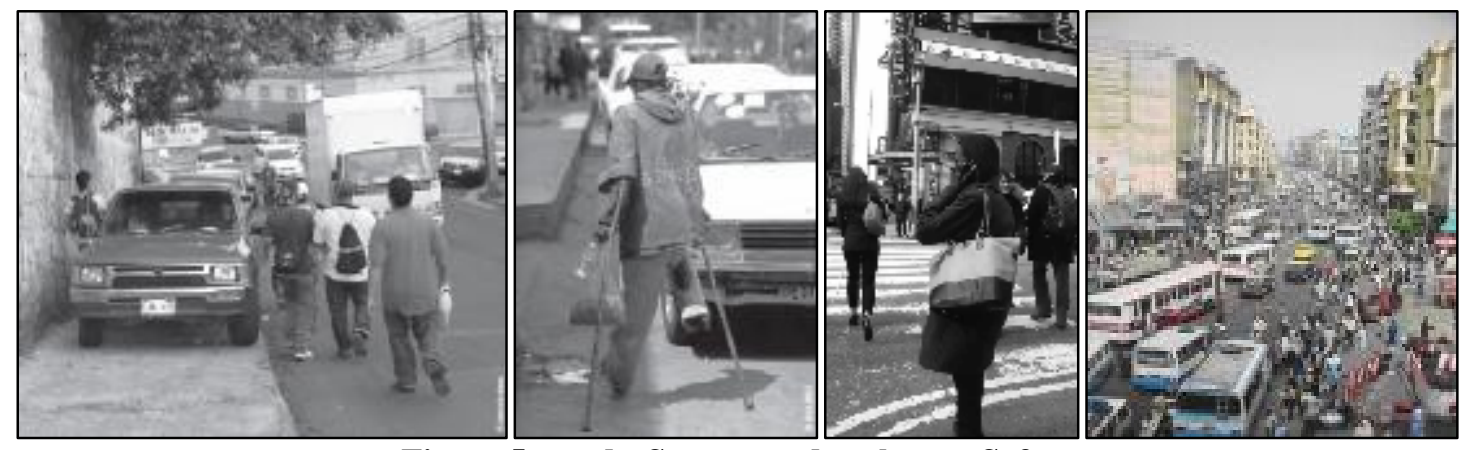

Figure 5: roads, Streets, and pathways Safety

Source: (WHO, 2013b)

Also, many authors noted that Pedestrian risk is increased when roadway design and land-use planning fail to plan for and provide facilities such as sidewalks, or adequate consideration of pedestrian access at intersections [19] [20]. Infrastructure facilities and traffic control mechanisms that separate pedestrians from motor vehicles and enable pedestrians to cross roads safely are important mechanisms to ensure pedestrian safety, complementing vehicle speed and road system management [21] .

Several other factors that contribute to pedestrian injury include, inadequate enforcement of traffic laws, unsafe driving practices, driver $>$ pedestrian distraction including mobile phone use, driver fatigue, pedestrian-vehicle conflict at pedestrian crossing points, reduced reaction time and reduced walking speed for the elderly, and finally lack of supervision of children who are too young to make safe judgments. [22][23]

\section{4) AGING PEOPLE'S NEEDS IN THE NEIGHBORHOOD STREETS AND PATHWAYS}

Many authors noted that the mobility of Aging people needs to be safe, direct, short [24], beautiful [25], and suitable pedestrian pathways. These pathways include shaded areas (especially in sunny and tropical countries), seats for rest [26], public toilets [27], and aesthetic objects (landmarks, natural formations, distinctive structures). On the other hand (Elizabeth Burton and Lynne Mitchell., 2006) determined six main attributes of suitable streets and pathways for Aging people. These attributes includes Familiarity, Legibility, Distinctiveness, Accessibility, Comfort and safety. Familiarity means how pathways and streets are easily understood by aging people. Familiar pathways and streets are hierarchical and long established with forms, open spaces, buildings and features in designs familiar to aging people. Legibility means how pathways and streets help aging people to understand where they are and to identify which way they need to go. Legible pathways and streets have an easy to understand network of routes and junctions with simple, explicit signs and visible, unambiguous features. Distinctiveness relates to the extent to which streets give a clear image of where they are, what their uses are and where they lead. Distinctive streets reflect the local character of the area and have a variety of uses, built form, features, colors and materials that give the streets and buildings their own identity within the overall character of the neighborhood. Accessibility refers to the extent to which streets enable older people to reach, enter, use and walk around places they need or wish to visit, regardless of any physical, sensory or mental impairment. Accessible streets have local services and facilities, are connected to each other, have wide, flat footways and ground level signal-controlled pedestrian crossings. Comfort refers to the extent to which streets enable people to visit places 
of their choice without physical or mental discomposure and to enjoy being out of the house. Comfortable streets are calm, welcoming and pedestrian-friendly with the services and facilities required by older people and people experiencing temporary or permanent incapacity. Safety refers to the extent to which streets enable people to use, enjoy and move around the outside environment without fear of tripping or falling, being run-over or being attacked. Safe streets have buildings facing onto them, separate bicycle lanes and wide, welllit, plain, smooth footways. [16]
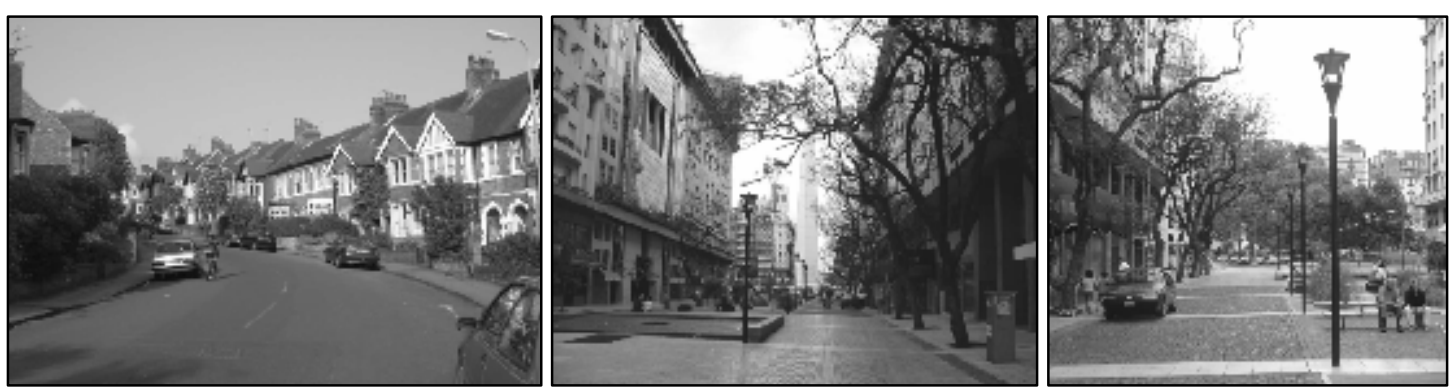

Figure 6: Aging people needs in their neighborhood streets and pathways

Left: Gently winding streets with varied form and features are more interesting than straight uniform streets.

Middle: Distinctive structures catch the eye and help people to identify which way they need to go. Right: Aging people with dementia tend to prefer informal urban open spaces to empty, formal squares Source: (Elizabeth Burton and Lynne Mitchell., 2006)0

\section{5) CONCLUSIONS AND RECOMMENDATIONS}

The paper concludes that Aging people have many difficulties and problems in using their neighborhood streets and pathways. Also, The paper concludes that Aging people have special needs in neighborhood streets and pathways. These needs should be integrated in the neighborhood planning and design. Consequently, it is recommended that neighborhood streets and pathways should be inclusively planned and designed. It means that these neighborhood streets and pathways should be familiar, legible, distinctive, accessible, comfortable and safe not only for aging people but also for everyone including, kids, young people, and handicapped people.
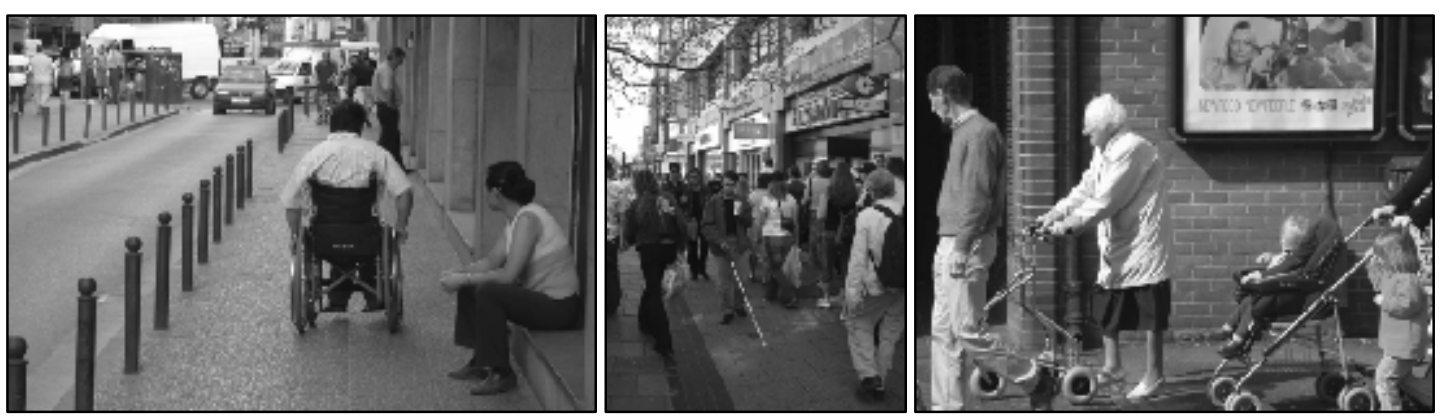

Figure 7: Inclusive Streets planning and design should addresses the needs of everyone, Kids, Aging people, younger people with any impairments

Source: (Elizabeth Burton and Lynne Mitchell., 2006)

These attributes could be achieved through keeping many points, including but not limited to:

B Streets \& footways geometry

- A hierarchy of street types, including main streets, side streets, lanes and footpaths.

- Short, well-connected, and gently winding streets with open ended bends and corners greater than $90^{\circ}$.

- Forked, staggered and T-junctions rather than cross-roads.

- Flat footways separated from traffic and bicycle lanes, with at least $2 \mathrm{~m}$ wide, and provided with Public seating, public toilets, and Telephone boxes . 

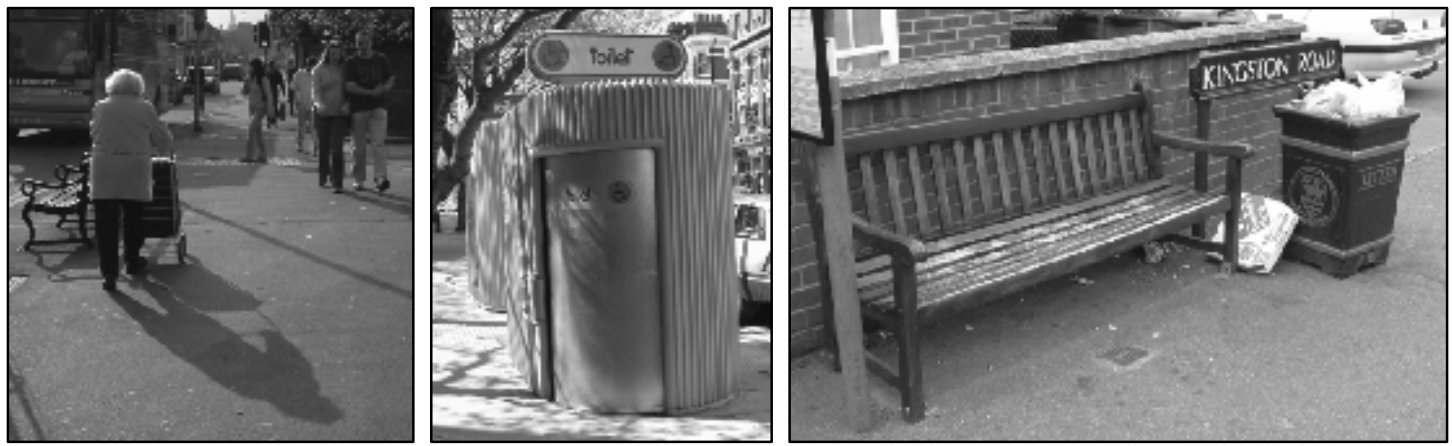

Figure 8: Aspects of recommended Streets \& footways geometry

Left: Flat footways separated from traffic and bicycle lanes, with at least $\mathbf{2}$ m wide.

Middle: footways provided by public toilets.

Right: footways provided by Public seating.

\section{B Streets' slopes, paving \& lighting}

Source: (Elizabeth Burton and Lynne Mitchell., 2006)

- Gentle slopes are preferred than using steps where slight level changes are unavoidable, Also using steps and a ramp with a maximum gradient of 1 in 20 could be used where greater level changes are unavoidable.

- Level changes (where unavoidable) that are clearly marked and well lit with guards, handrails and non-slip, non-glare surfaces

- Flat, smooth, plain, non-slip, and non-reflective paving in clear color and textural contrast to walls, bicycle lanes and traffic calming measures.

- Street lighting adequate for aging people with visual impairments
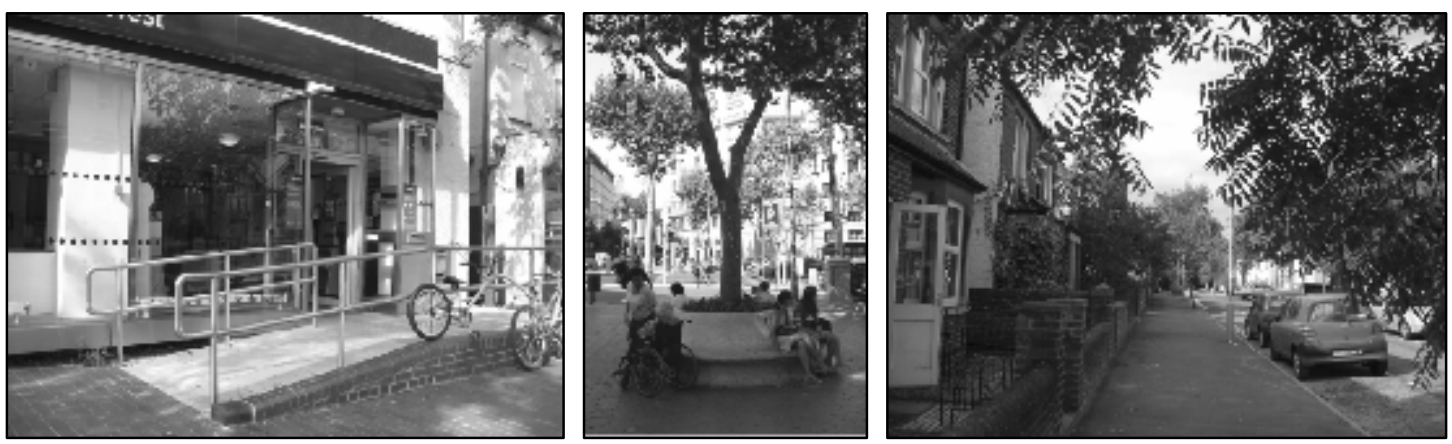

Figure 9: Aspects of Streets' slopes and paving

Left: small changes in level should have both a ramp and steps.

Middle: Open spaces should have quiet, shaded seating areas.

Right: Footways should be wide with plain, smooth, level, non-slip and nonreflective paving.

Source: (Elizabeth Burton and Lynne Mitchell., 2006)

\section{B Streets' signs}

- Minimal signs giving simple, essential and unambiguous information at decision points.

- Signs with large, realistic graphics and symbols in clear color contrast to the background, generally with dark lettering on a light background.

\section{ß Other related points}

- Places, buildings and street furniture are in designs familiar to or easily understood by aging people.

- Low walls, fences and hedges and open fencing separating private and public space.

- A variety of places of interest, activities, aesthetic and practical features, such as trees and street furniture.

- A mix of land uses; Housing located no further than $500 \mathrm{~m}$ from local primary services, including food store, post office, bank, health center, green space, public toilets, public seating and public transport stops. 


\section{REFERENCES}

[1] United Nations, General Assembly (UN-GA), 2011; Follow-up to the Second World Assembly on Ageing; Report of the Secretary-General; A/66/173

[2] United Nations, Department of Economic and Social Affairs، Population Division (UNDESA-PD), 2015; World Population Prospects - The 2015 Revision: Key Findings and Advance Tables; Working Paper No. ESA/P/WP.241

[3] United Nations, Department of Economic and Social Affairs, Population Division (UNDESA-PD), 2017; World Population Ageing 2017 - Highlights (ST/ESA/SER.A/397).

[4] Gorman M., 1999; Development and the rights of older people. In: Randel J, et al., Eds.; The ageing and development report: poverty, independence and the world's older people; London; Earthscan Publications Ltd.

[5] Thane P., 1978; The muddled history of retiring at 60 and 65; New Society; 45(826).

[6] Glascock AP, Feinman SL., 1980; A holocultural analysis of old age. Comparative Social Research.:3.

[7] Perrv. C., 1998; The Neighborhood Unit (1929) Reprinted; Routledge/Thoemmes, London.

[8] Lawhon. L.. 2009: The Neighborhood Unit: Physical Design or Physical Determinism?; Journal of Planning History, 8.

[9] MacIver, R.M., 1970; Community: A Sociological Study; fourth edition; FRANK CASS \& CO. LTD.

[10] AlWakil, Shafak., 2007. Urban planning: Housing - Services - Mobility; Second Part; Arabic Edition; Icopa, Cairo.

[11] Schuck, A. M., \& Rosenbaum, D. P., 2006; Promoting safe and healthy neighborhoods: What research tells us about intervention; In K. Fulbright-Anderson, \& P. Auspos (Eds.), Community change: Theories, practice, and evidence; Washington: The Aspen Institute.

[12] Allam, Ahmed. K., 1991; City planning; Arabic Edition; Anglo Egyptian Library; Cairo.

[13] E. White, 1999; Path-portal-place. In: Matthew Carmona and Steve Tiesdell Eds., 2007; Urban Design Reader; Architectural Press, Elsevier Ltd.

[14] Lynch, K., 1960; The Image of the city; THE TECHNOLOGY PRESS \& HARVARD UNIVERSITY PRESS; CAMBERDIGE.

[15] Jacobs, A., 1993; Greet streets; The M.I.T press, Cambridge Massachusetts, London.

[16] Elizabeth Burton and Lynne Mitchell., 2006; Inclusive Urban Design: Streets for Life; Architectural Press; imprint of Elsevier; Linacre House, Jordan Hill; Oxford.

[17] World Health Organization (WHO), 2013a; Global status report on road safety 2013: supporting a decade of action; Geneva.

[18] Peden M et al., eds., 2004; World report on road traffic injury prevention.; World Health Organization; Geneva.

[19] Zegeer CV, Bushell M., 2012; Pedestrian crash trends and potential countermeasures from around the world.; Accident Analysis \& Prevention; 44:3- 11.

[20] Sleet DA, Naumann RB, Rudd RA., 2011; Injuries and the built environment. In: Dannenberg AL et al. eds. Making healthy places: designing and building for health, well-being and sustainability. Washington, DC, Island Press.

[21] World Health Organization (WHO), 2013b; Pedestrian safety: A road safety manual for decision-makers and practitioners; On website: https://www.who.int/roadsafety/publications/en.

[22] Elvik R, et al., 2009; The handbook of road safety measure; 2nd ed. Bingley; Emerald Group Publishing Limited.

[23] Crandall JR, Bhalla KS, Madeley NJ., 2002; Designing road vehicles for pedestrian protection; British Medical Journal, 324: 1145-1148.

[24] Perez. F. et al., 2001; Aging in Place; Predictors of the residential satisfaction of elderly; Kluwer Academic Publishers; Social Indicators Research 54. 
[25] Cliff Moughtin et al., 1999; URBAN DESIGN: ORNAMENT AND DECORATION; Second Edition; Architectural Press; An imprint of Butterworth-Heinemann; Linacre House, Jordan Hill, Oxford.

[26] BaSabrine, Sakina M. \& Nakity, Noha A., 2008; New Housing and It's Suitability For elderly in Jeddah city; Arabic edition; Design Issues in the third century Conference; Faculty of Applied Arts; Cairo, Egypt.

[27] Clara Greed., 2009; Inclusive Urban Design: Public Toilets; Architectural Press; imprint of Elsevier; Linacre House; Jordan Hill; Oxford. 